\title{
From "Wildland-Urban Interface" to "Wildfire Interface Zone" using dynamic fire modelling
}

\author{
$\underline{\text { K.G. Tolhurst }}^{\text {a }}$, T.J. Duff ${ }^{\text {ab }}$ and D.M. Chong ${ }^{\text {ab }}$ \\ ${ }^{a}$ Department of Forest and Ecosystem Science, University of Melbourne, Creswick, Victoria \\ ${ }^{b}$ Bushfire Cooperative Research Centre, Melbourne, Victoria \\ Email:kgt@unimelb.edu.au
}

\begin{abstract}
The interface zone in relation to wildfires has been defined in many ways. Some definitions have been tailored for particular applications. There is no consistent way of defining the interface or demarcating it on the ground. Current definitions are based more on the ease of application rather than the likely penetration of a wildfire into a residential area. There is a need to have a more consistent and relevant definition of the interface zone for planning, warnings and regulations. The reality is that the interface zone at a particular location will vary depending on the weather, fuel, scale of fire and terrain at any one time so these factors should be included in defining the interface zone.
\end{abstract}

The interface zone has been referred to in several different ways: it has been called the "I-Zone", "WildlandUrban Interface (WUI)", "Rural-Urban Interface", "Urban-Interface", "Chaparral-Urban Interface" (Radtke, 1983) and possibly others. These names themselves contribute to a level of confusion when talking about exposure to wildfire. Interestingly, all the names are euphemisms for what is really of interest - the interface with wildfire.

The term "interface" implies a zone where residential areas and wildfires will mix. The extent of the wildfire interface is therefore the extent to which a wildfire can penetrate a residential area before it either selfextinguishes or transitions into an urban fire where the progression becomes dominated by structure-tostructure ignition rather than via wildland fuels. It therefore follows that the majority of house loss caused by wildfires would occur in what we propose should be called the "Wildfire Interface Zone" (WIZ).

Dynamic wildfire characterization simulators such as PHOENIX RapidFire (Tolhurst et al., 2008) have provided a means for defining the Wildfire Interface, taking into account potential fire size, intensity and ember density. PHOENIX RapidFire takes into account the spatial and temporal distribution of fuels, fire, weather, terrain, ignition time and location and modifications to fuels caused by recent fires or other fuel modification works and disruptions to fuels caused by roads, rivers, fuelbreaks, and other linear fuel-free areas.

Some preliminary analyses have shown that it is not just the fuel within some set distance (e.g. $40 \mathrm{~m}, 100 \mathrm{~m}$ ) of a residential area that affects the probability of house loss by wildfire, but a combination of all the factors that contribute to wildfire behaviour. PHOENIX RapidFire can be used to define the Wildfire Interface Zones based on local fuels, terrain and climate. We therefore propose a new definition of the Wildfire Interface Zone be adopted to replace the concept of WUI:

"The area where dwellings, or flammable material in contact with dwellings, have the potential to be ignited by exposure to any combination of flame, radiation, embers, firebrands or hot gases from a wildfire. It does not include areas only exposed to smoke, ash or charred material from a wildfire.

The extent of the actual Wildfire Interface Zone will depend on the nature of the fuels, weather, topography, seasonal conditions and scale of wildfires in that geographic location at a given point in time, but for planning purposes the extent of the potential Wildfire Interface Zone can be determined for a stated set of conditions."

Keywords: Wildland-Urban Interface, PHOENIX RapidFire, Wildfire Interface Zone, dynamic fire modelling, ensemble simulation, fire spread model 


\section{INTRODUCTION}

There is a growing literature on the definition and management of the Wildland-Urban Interface (WUI). The purposes for defining the WUI differ greatly, varying from the need to manage the surrounding wildlands (e.g. Gibbons et al., 2012), the need to assess the insurance risk (e.g. Chen and McAneney, 2004), and the need for community fire awareness and for urban development planning (e.g. Mell et al., 2010). As pointed out by Mell et al. (2010), "A definition of WUI land areas has not been unequivocally determined". What is common to all of these efforts is the need to define "urban", "wildland" and the "interface".

There is no single definition of "urban" when considering the Wildland-Urban Interface. Lampin-Maillet et al. (2010), defined 4 types of building configuration: isolated, scattered, dense clustered and very dense clustered. Mell et al. (2010) and Stewart et al. (2003) defined 3 types of configuration: interface, intermix and occluded, but the criteria for each type varied. For example, Mell et al. (2010) used the US Federal Register's definitions in defining interface areas as being those with greater than 7.5 house/ha or 1 person/ha (250 people per square mile) (based on census data), intermix area had more than 1 house/16 ha (40 acres) or more than 0.11 people/ha, and occluded (wildland) was where houses in an otherwise urban area might abut an isolated area of wildland, but the wildland was less than 400 ha (1000 acres) in size (US Department of the Interior (USDI) and US Department of Agriculture (USDA), 2001). In contrast, Stewart et al. (2003) defined interface as having more than 1 house $/ 16$ ha and less than $50 \%$ vegetation cover, intermix was where house density was more than 1 house $/ 16$ ha, but more than $50 \%$ vegetation cover and occluded was not considered, but the intermix and interface areas were areas within $2.4 \mathrm{~km}$ of extensive wildlands - the assumed maximum extent of ember caused spotfires (spotting). Other authors have other variations around these. The differences are due, in part, to the tools and data used to map the WUI areas.

What constitutes being defined as "wildland" has also varied between authors and the tools used to map it. A recent study of defining areas of wildland based on observed house loss in the 2009 Victorian bushfires, defined an area of wildland as being an area of native trees of greater than 0.4 ha with a minimum width of $22 \mathrm{~m}$ (Newnham et al., 2012). They found that the probability of house loss decreased exponentially with distance from wildlands defined in this way which is consistent with studies elsewhere (e.g. Chen and McAneney, 2004; Ahern and Chladil, 1999). Unlike Stewart et al. (2003), Newnham et al. (2012) did not limit the extent of consideration to $2.4 \mathrm{~km}$ since grassland and other vegetation types are sufficiently flammable to carry a wildfire to isolated patches of wildlands and in any case, the potential spotting distances in Australia can be up to $36 \mathrm{~km}$, not just $2.4 \mathrm{~km}$ (Tolhurst, 2009). Chen and McAneney (2010) defined the wildland (bushland) areas associated with building damage as being "typically continuous and large with the smallest patch size of $1.6 \mathrm{ha}^{\mathrm{N}}$. They claimed that the delineation of the wildland boundary with sufficient accuracy to critically determine the separation distance of a building from the wildland required highresolution imagery $(\leq 2.5 \mathrm{~m}$ resolution) which is consistent with the work of Newnham et al. (2012) which used 1.12 laser pulses per square metre. Where the wildland boundary is sharp and unambiguous, mapping is easily achieved. However, there still remains some difficulty when forest has been thinned to various degrees. In such situations, percentage canopy cover, as used by Stewart et al. (2003), may be useful.

The Wildland-Urban Interface is generally thought of as being areas where a clearly demarcated urban area and a clearly defined wildland area meet, but in reality there is a continuum. This mis-match between what is convenient and what is reality has resulted in some undesirable management, planning and legal issues. Therefore a more functional redefinition of a "Wildland-Urban Interface" is required.

The intent of defining the Wildland-Urban Interface centres around wildfires, therefore we propose here to refer to this area as the "Wildfire Interface Zone" (WIZ).

Some work has already been undertaken to better define the Wildfire Interface Zone by Radke (2007) and the Australian Standard for the construction of buildings in bushfire-prone areas (AS 3959-2009) (Standards Australia, 2009). Radke used a static, GIS-based, cellular approach, combining fuel, weather and topography with a wildfire model. The advantage of using a fire behaviour model was that it integrated the contribution of the terrain, fuels and weather conditions at a location to describe the nature of the fire exposure - e.g. fire intensity and flame height. Radke's approach required sub-metre mapping of fuels in the WUI, hi-resolution weather $(10 \mathrm{~m})$ and hi-resolution DEM (terrain). Radke found he could not apply the standard fuel types used in the United States for describing the urban interface fuels and so he developed his own classification which included the fuels associated with the buildings (Radke, 1995). The Australian Standard (AS 3959-2009) estimates the exposure to radiation or flame contact based on set weather conditions for a given geographic location, the slope of the ground within $100 \mathrm{~m}$ of a dwelling, the distance to the nearest flammable vegetation and the vegetation type. Like Radke's approach (Radke, 2007), the Australian Standard (AS 3959-2009) 
considers the fuel, weather and topography in the immediate vicinity of a dwelling, however the approach taken by the Australian Standard is more static than Radke's approach and is less quantitative.

Both Radke and Standards Australia have acknowledged the importance of characterizing the wildfire hazard. However, neither approach adequately quantifies two major fire hazards - embers (firebrands) and fire-induced winds. Radke (2007) talks about "firestorms" where fire-induced winds occur, but his model does not quantify or spatially describe these winds. Similarly, the Australian Standard (AS 3959-2009) acknowledges the importance of embers in house ignition, but does not quantify or spatially describe ember density or distribution, despite of the fact that more than $90 \%$ of all house losses involve embers alone or in combination with other types of fire exposure (Blanchi et al., 2006).

In this paper, we will describe how a dynamic fire simulation model, PHOENIX RapidFire (Tolhurst et al., 2008) can be used to integrate the factors that contribute to fire behaviour (fuel, weather, topography and fire scale) to describe the likely fire characteristics at the point of a house (radiation, convective strength, flame contact, embers). A function that combines the three main fire hazards to the probability of house loss (ember density, convective strength and flame height) has already been developed (Tolhurst and Chong, 2011) and is applied here. This, with other factors, will be used to explore the extent of the Wildfire Interface Zone (WIZ) in the case of a small rural town in west-central Victoria and compare this with the WUI defined using some other existing methods.

\section{METHOD}

\subsection{Fuels}

Fine fuels across the State of Victoria (about 22.7 Mha) were mapped by grouping about 700 vegetation types into about 40 fuel types. Each fuel type was described in strata representing the combined surface and near-surface, elevated and bark (on tree stems) fine fuel (Hines et al., 2010). Each stratum of each fuel type was assigned a maximum fuel level as might be expected in a long-unburnt situation in a normal growing season. In this study, all fuels were considered to be long-unburnt, but normally fire history would be used to estimate the fuel level as it reaccumulates with time since fire. In this case-study, the main fuel types were: grazed temperate grassland, grassy woodland, shrubby foothill forest, herb-rich foothill forest, softwood plantation, rural residential and urban. Urban fuels are areas where the majority of the vegetation is cultivated gardens in between houses, roads and other developments. Rural residential areas are defined as areas where much of the area is still potential wildfire fuel, but the remnant native vegetation covers less than $50 \%$ of the area and houses, other buildings and pavements cover less than $10 \%$ of the area (Fig. 1). Fuels were mapped at $30 \mathrm{~m}$ resolution.

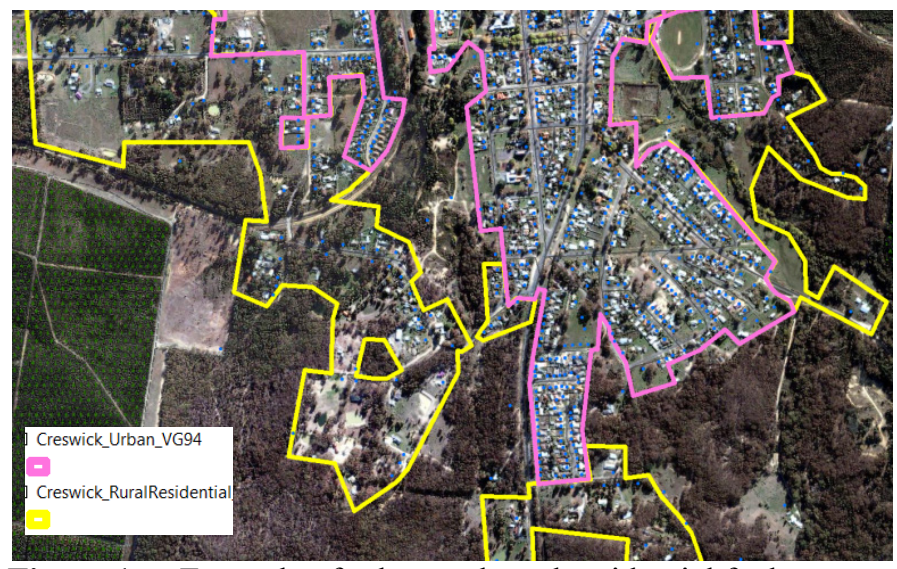

Figure 1. Example of urban and rural residential fuel types.

\subsection{Topography}

Topography was mapped using a digital elevation model (DEM) dataset for the whole State. This DEM was mapped at $30 \mathrm{~m}$ horizontal resolution and $1 \mathrm{~m}$ vertical resolution.

\subsection{Weather}

Three historic weather streams were used: Black Saturday (7 Feb 2009), Ash Wednesday (16 Feb 1983) and the day of the Muskvale fire following Black Saturday (23 Feb 2009). All three weather streams were from extreme weather events and showed a broadly similar pattern - a strong north-westerly wind ahead of a strong southwesterly wind change. Historically, this is the pattern of weather for large and damaging wildfires (Mills, 2009). The maximum forest fire danger index (FFDI) (McArthur, 1967) for the case-study area on Black Saturday was 180, for Ash Wednesday it was 120, and for the day of the Muskvale fire it was 50. These weather patterns were scaled to give nominal FFDI values of 25, 50, 100 and 150 . Scaling was achieved by simultaneously changing the air temperature, relative humidity and wind speed, e.g. to scale the Muskvale weather conditions from an FFDI of 50 to 100, air temperature was increased by $30 \%$, relative humidity was 
decreased by $30 \%$ and wind speed was increased by $30 \%$. This kept the pattern of weather the same, but changed the burning conditions in a way often reflected by increasingly severe fire weather.

A single weather stream was used for each simulation. As the area of each fire was within a $100 \mathrm{~km} \times 100$ $\mathrm{km}$ area and the elevation range was only about $200 \mathrm{~m}$, weather was assumed to be similar across the casestudy area. Weather variables were recorded hourly and linearly interpolated for use in fire simulations.

\subsection{Fire}

The fire characteristics were simulated using PHOENIX RapidFire. PHOENIX RapidFire is a dynamic, mechanistic, spatially continuous, empirical fire characterization computational model. Unlike Radke's approach (Radke, 2007), PHOENIX RapidFire "spreads" the fire in a spatially and temporally explicit fashion. The time steps used in the model depend on the rate of spread of the fire and vary from about one minute to 20 minutes. Fire spread is computed using Huygen's wavelet principle (Anderson et al., 1982) and represents the fire front as a series of points forming a continuous line. Fuel strata were dynamically included or excluded in the fire behaviour calculations depending on the flame height calculated for the given weather and slope conditions and supported by the combined surface fine fuel. No effect of suppression was included in this study. The effect of linear fuel disruptions such as roads, rivers and firebreaks was included by locally reducing the intensity of the fire by a factor dependent on the width of the disruption. Input and output data to the model were averaged in cells $120 \times 120$ metres. This cell size was found, from some preliminary trials, to provide the best resolution of fuel details and fire behaviour in interface areas.

An example of the type of output produced by PHOENIX RapidFire running in "GridAnalysis" mode is shown in Figure 2. The $\mathrm{x}$ and y coordinates are the centroids of the $120 \mathrm{~m}$ cells and can easily be displayed or used with GIS software. The output data is a summary of the impact of a number of independent fires impacting on each cell.

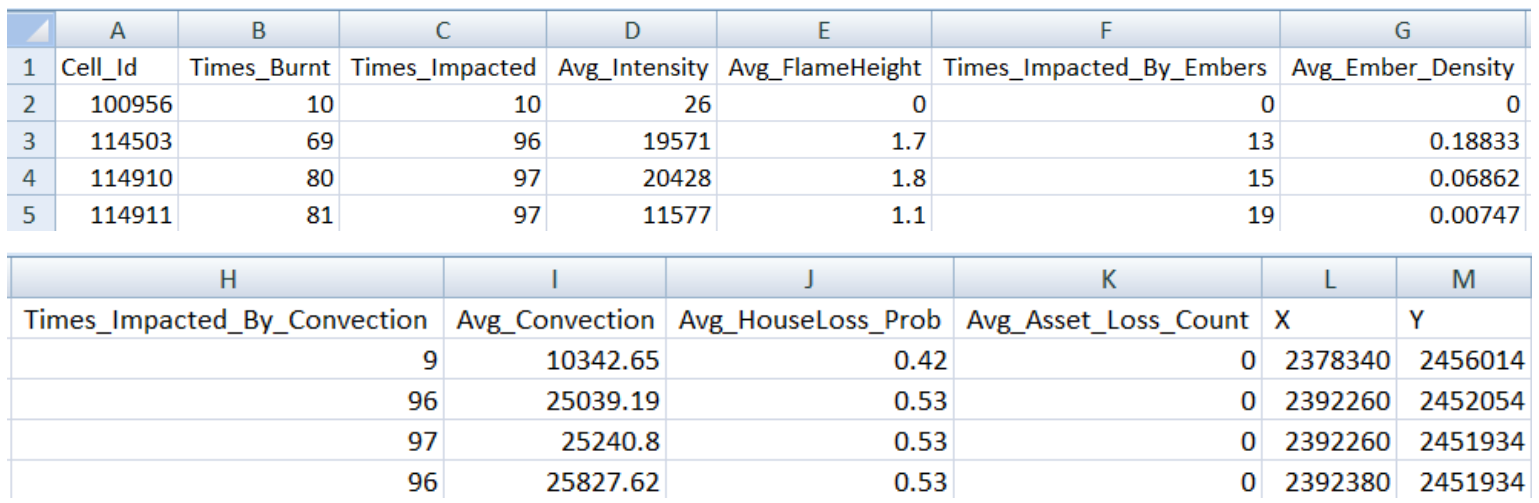

Figure 2. Example of output variables for a simulation from PHOENIX RapidFire running in "GridAnalysis" mode.

A grid of fire initiation points was used to simulate independent fires starting across the landscape. The spacing of the ignition points was $2 \mathrm{~km} \mathrm{x} 2 \mathrm{~km}$ within a $40 \mathrm{~km} \mathrm{x} 40 \mathrm{~km}$ area, resulting in 370 independent fires for each weather scenario tested, therefore the combined effect of 1110 fires were used for each FFDI level tested. Fires were ignited at $1300 \mathrm{~h}$ and run until $2330 \mathrm{~h}$.

\section{RESULTS}

Mapping house density at a resolution of 16 ha (40 acres) as used in the USA provided a good general match with the subjective aerial photo interpretation used in this case-study (Fig. 3). House densities of less than 1 house per 16 ha ( 0.0625 houses/ha) corresponded well with the "Rural" areas, house densities between 1 and 16 house per 16 ha corresponded well to the "Rural Residential" areas mapped here and house densities greater than 16 houses/16 ha (1 house/ha) corresponded well to "Urban" areas. 


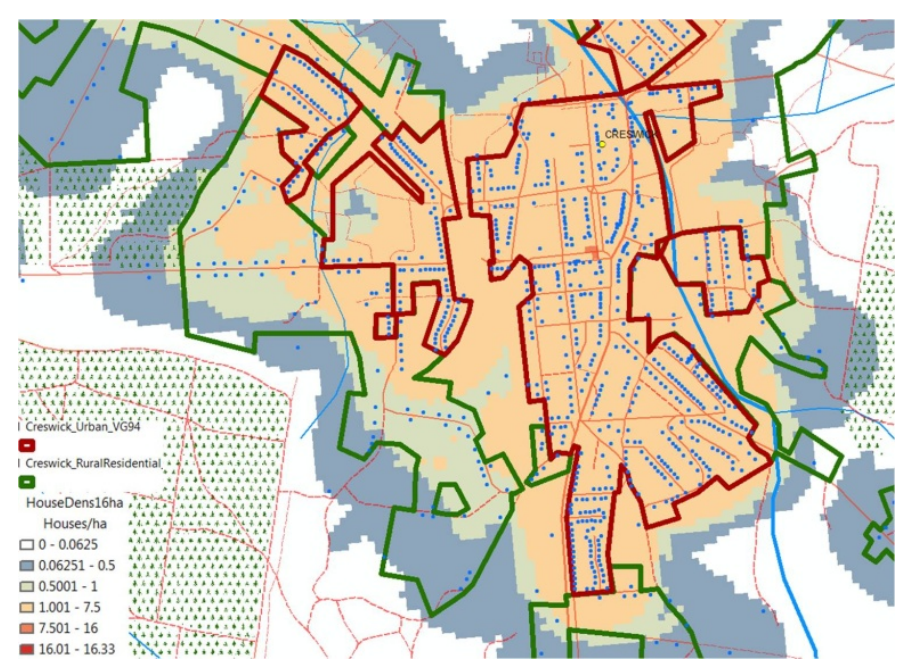

Figure 3. Comparision between house density analysis and subjective mapping.

Areas of the case-study assessed to be most at risk from a wildfire differ greatly depending on the method of assessment used. Figure 4A shows the probability of house loss predicted by PHOENIX RapidFire averaged for the three weather scenarios with a Forest Fire Danger Index of 100. The extent of the area where there is a $50 \%$ or greater chance of house loss (Tolhurst and Chong, 2011) (pale yellow) is not symmetrically distributed across the urban or rural residential areas. The area of greatest potential house loss is on the northern, western and southern sections of the residential areas with little loss predicted on the eastern edges. However, the extent of potential loss is much greater under more severe fire weather (Fig. 4B) even if the general pattern is similar. This contrasts with Figure $4 \mathrm{C}$ which shows the distance from the wildland interface where areas within 50 metres of the wildland would be expected to have about $60 \%$ house loss (Chen and McAneney, 2010) regardless of the direction. Figure 4D shows the estimated radiation exposure $\left(\mathrm{kW} / \mathrm{m}^{2}\right)$ of a house $10 \mathrm{~m}$ from the wildland interface, using the assumptions in the Australian Standard AS 3959-2009 (Standards Australia, 2009), but based on the average predicted flame height from PHOENIX RapidFire. This distribution of radiation exposure ("Bushfire Attack Levels") is also asymmetrical because of the simulated fire results.

In addition to the average potential impact and consequence of fires, there is also the issue of likelihood likelihood that a fire might start and the likelihood that should a fire start, that it reaches the assets or values of interest. This relative ignition likelihood could be used to weight the impact of each fire on asset loss, although it was not done in this case study. The second aspect of likelihood relates to the probability that once a fire is started that it will impact on a specific area. This is a reflection of the prevailing winds, terrain and fuels and whilst it is possible to have assets lost in a particular part of an area it might be much more or less likely than asset loss in another part of the area. A third aspect of likelihood is the likelihood of weather conditions matching those used in the simulation. It is much more likely for the case-study area to experience a day when the Forest Fire Danger Index (FFDI) reaches 50 than it is 150 . The FFDI in the study area might reach 50, 20 times in a decade, but reaching 150 might be a 1 in 50 year event. Both the potential consequence and likelihood of occurrence are important when assessing the level of risk.

\section{DISCUSSION}

The extent of the Wildfire Interface Zone has been shown to vary with the severity of the weather conditions as expressed by the Forest Fire Danger Index and the nature of the fuels as distinguished between the rural, rural-residential and urban areas. The return period for different levels of FFDI varies across the country and so it is important to capture this variation for consistent mapping of the Wildfire Interface Zone (WIZ) across the country if consistent design criteria are to be used. Currently, the Australian Standard (AS 3959-2009) only uses a very simplistic application of the design FFDI.

As discussed in Radke (2007), defining the areas of residential density is not as important as describing the nature of the fuels across the landscape, especially in areas with dwellings. The extent of the Wildfire Interface Zone is limited in urban areas if a wildfire cannot continue to propagate through it due to the lack of fuels. In such a case, the wildfire impact will diminish at an exponential rate with the distance downwind from the wildfire extent (Chen and McAneney, 2010). Therefore, it is not the house density that is as important as the availability and continuity of fine fuels to propagate the wildfire and the limits to propagation are determined, in part, by the severity of the weather conditions as seen in Fig.4. House to house ignition can be a significant factor in the total number of houses lost, but while this process might be initiated by a wildfire, this is essentially a township or building fire spread issue not wildfire.

The extent of the Wildfire Interface Zone is not symmetrical when determined by dynamic simulation because the weather, fuels and terrain are not uniform as are assumed in some methods of interface definition (e.g. Chen and McAneney, 2010; US Department of the Interior (USDI) and US Department of Agriculture 
(USDA), 2001). Therefore, the total extent of the Wildfire Interface Zone is likely to be less than what might be determined by these fixed definitions of areas at risk.

The "Bushfire Attack Level" determined using the Australian Standard (AS 3959-2009) only considers exposure to radiation. A dynamic simulation of fire that characterizes ember density, radiation, and convective strength will better capture the real exposure hazard experienced by a dwelling.
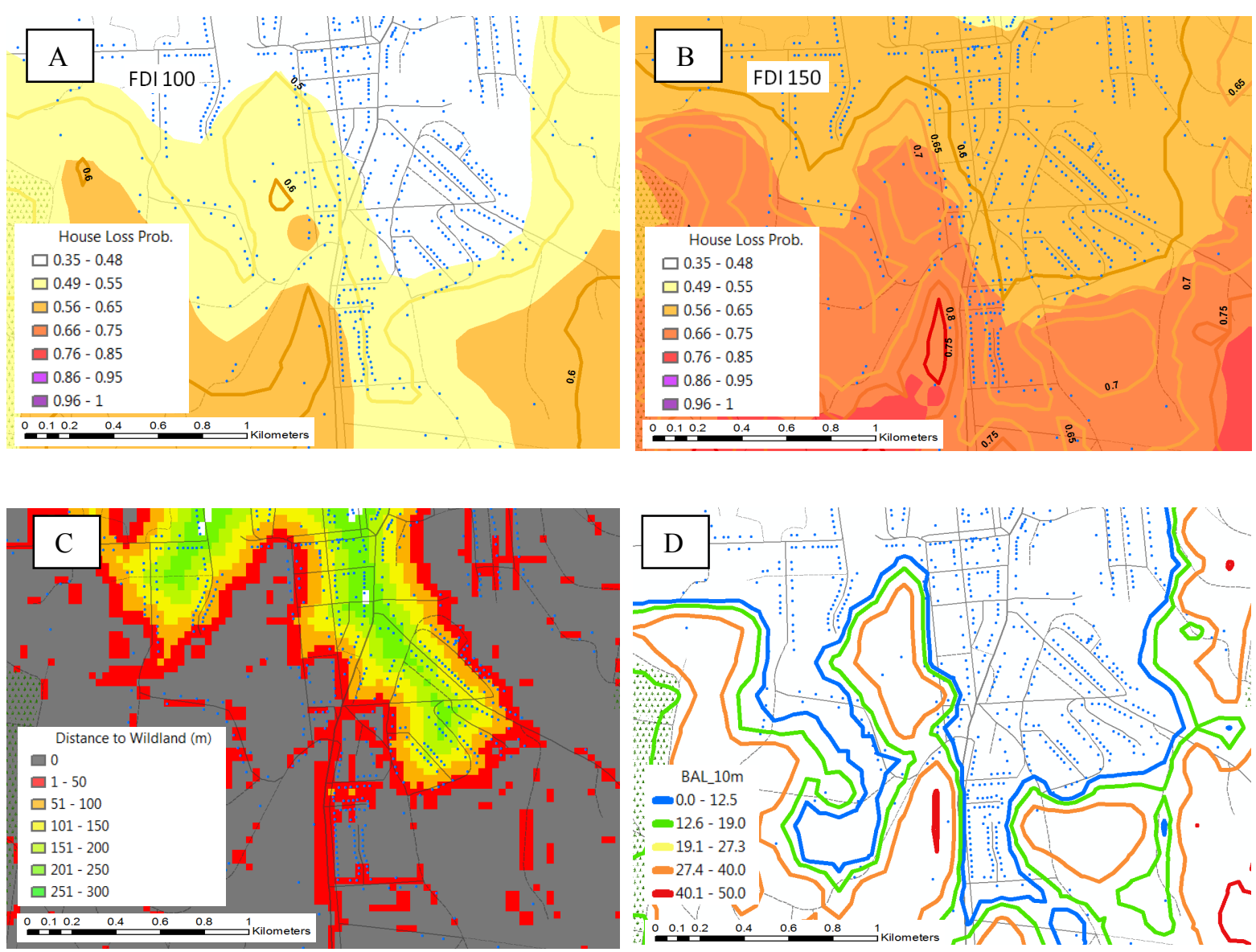

Figure 4. House loss probability/wildfire exposure as assessed using PHOENIX RapidFire simulations with a Forest Fire Danger Index of 100 (A) and 150 (B), using the distance to wildland (C) and using "Bushfire Attack Levels" based on radiation exposure $10 \mathrm{~m}$ from average simulation flame height (D).

\section{CONCLUSIONS}

What is commonly referred to as the Wildland-Urban Interface (WUI) does not adequately describe areas at risk from wildfires. We propose a fire-centric approach. We suggest dynamic wildfire simulation be used with location specific fuel, weather and terrain information to define the "Wildfire Interface Zone" (WIZ) with a specified level of house loss probability. This provides a more consistent and generally applicable approach to risk assessment.

It is important to consider the whole fire context when considering wildfire risk. A systematic approach to identifying the design criteria for risk assessment, such as the return period for the weather conditions used and level of ignition risk, is needed. A fire simulation tool such as PHOENIX RapidFire is a useful way of integrating complex, interacting factors and should be used to define the Wildfire Interface Zone. Mitigation treatments such as fuel modification and firebreaks can then be objectively assessed as to their benefits in terms of cost/benefit and risk reduction. 


\section{REFERENCES}

Ahern, A. \&Chladil, M. (1999). How far do bushfires penetrate urban areas? In Australian Disaster Conference, 21-26 Canberra: Emergency Management Australia.

Anderson, D. H., Catchpole, E. A., de Mestre, N. J. \&Parkes, T. (1982). Modelling the spread of grass fires. Journal of Australian Mathematics Society, Series B 23: 451-466.

Blanchi, R., Leonard, J. E. \&Leicester, R. H. (2006). Bushfire risk at the rural/urban interface. In Australasian Bushfire ConferenceBrisbane: Griffith University.

Chen, K. \&McAneney, J. (2004). Quantifying bushfire penetration into urban areas in Australia. Geophysical Research Letters 31: L12212.

Chen, K. \&McAneney, J. (2010). Bushfire penetration into urban areas in Australia: A spatial analysis (CRC.304.001.0029). 32: Victorian Bushfire Royal Commission.

Gibbons, P., van Bommel, L., Gill, A. M., Cary, G. J., Driscoll, D. A., Bradstock, R. A., Knight, E., Moritz, M. A., Stephens, S. L. \&Lindenmayer, D. B. (2012). Land management practices associated with house loss in wildfires. In Public Library of Science ONE, Vol. 7, e29212.

Hines, F., Tolhurst, K. G., Wilson, A. A. G. \&McCarthy, G. J. (2010). Overall fuel hazard assessment guide. Melbourne: Victorian Government Department of Sustainability and Environment.

Lampin-Maillet, C., Jappiot, M., Long, M., Bouillon, C., Morge, D. \&Ferrier, J. (2010). Mapping wildandurban interfaces at large scales integrating housing density and vegetation aggregation for fire prevention in the South of France. Journal of Environmental Management 91: 732-741.

McArthur, A. G. (1967). Fire behaviour in eucalypt forests. In Leaflet 107, 36 Canberra: Commonwealth Forestry and Timber Bureau.

Mell, W. R., Manzello, S. L., Maranghides, A., Butry, D. \&Rehm, R. G. (2010). The wildland-urban interface fire problem - current approaches and research needs. International Journal of Wildland Fire 19: 238-251.

Mills, G. A. (2009). Meteorological drivers of extreme bushfire events in southern Australia. In Modelling Workshop, 1-8 Melbourne, Australia: Centre for Australian Weather and Climate Research, http://www.cawcr.gov.au/events/modelling_workshops/workshop_2009/papers/MILLS.pdf.

Newnham, G. J., Siggins, A. S., Blanchi, R., Culvenor, D., Leonard, J. \&Mashford, J. S. (2012). Exploiting three dimensional vegetation structure to map wildland extent. Remote Sensing of Environment 123: 155-162.

Radke, J. (1995). Modeling urban/wildland interface fire hazards within a geographic information system. Geographic Information Science 1: 7-20.

Radke, J. (2007). Modeling fire in the wildland-urban interface: directions for planning. Advances in the Economics of Environmental Resources 6: 183-210.

Radtke, K. W. H. (1983). Living more safely in the chaparral-urban interface. In General Technical Report, Vol. PSW-67, 50: United States Department of Agriculture, Forest Service, Pacific Southwest Forest and Range Experiment Station.

Standards Australia (2009). Construction of buildings in bushfire-prone areas. Vol. AS 3959-2009, 128: SAI Global.

Stewart, S. I., Radeloff, V. C. \&Hammer, R. (2003). The wildland-urban interface in U.S. metropolitan areas. In National Urban Forest Conference Proceedings, 254-255 San Antonio, Texas.

Tolhurst, K. G. (2009).Report on he physical nature of the Victorian fires occurring on 7th February 2009. Vol. EXP.003.001.0017: Victorian Bushfires Royal Commission.

Tolhurst, K. G. \&Chong, D. M. (2011). Assessing potential house losses using PHOENIX RapidFire. In Proceedings of Bushfire CRC \& AFAC 2011 Conference Science Day, 74-86 (Ed R. P. Thornton). Sydney, Australia: Bushfire CRC.

Tolhurst, K. G., Shields, B. J. \&Chong, D. M. (2008). Phoenix: development and application of a bushfire risk management tool. The Australian Journal of Emergency Management 23(4): 47-54.

US Department of the Interior (USDI) \&US Department of Agriculture (USDA) (2001). Urban wildland interface communities within vicinity of federal lands that are at high risk from wildfire. Federal Register 66(3): 751-777. 